\title{
Efficacy of Letrozole as First-Line Treatment of Postmenopausal Women with Hormone Receptor-Positive Metastatic Breast Cancer in Korea
}

\author{
Seung Hoon Beom, MD' \\ Jisu Oh, MD2 \\ Tae-Yong Kim, MD, PhD 3 ,4 \\ Kyung-Hun Lee, MD, PhD 3,4 \\ Yaewon Yang, MD ${ }^{3,4}$ \\ Koung Jin Suh, MD \\ Hyeong-Gon Moon, MD ${ }^{3,5}$ \\ Sae-Won Han, MD, PhD 344 \\ Do-Youn Oh, MD, PhD ${ }^{3,4}$ \\ Wonshik Han, MD, PhD 3,5 \\ Tae-You Kim, MD, PhD 34 \\ Dong-Young Noh, MD, PhD 3,5 \\ Seock-Ah Im, MD, PhD 3 ,4
}

${ }^{1}$ Department of Internal Medicine, Yonsei University College of Medicine, Seoul, ${ }^{2}$ Department of Internal Medicine, CHA Bundang Medical Center, CHA University, Seongnam, ${ }^{3}$ Department of Internal Medicine, Seoul National University Hospital, Seoul, ${ }^{4}$ Cancer Research Institute, Seoul National University College of Medicine, Seoul, ${ }^{5}$ Department of Surgery, Seoul National University Hospital, Seoul, Korea

Correspondence: Tae Yong Kim, MD, PhD Department of Internal Medicine,

Seoul National University Hospital,

101 Daehak-ro, Jongno-gu, Seoul 03080, Korea

Tel: $82-2-2072-4748$

Fax: 82-2-762-9662

E-mail: ktyongmd@gmail.com

\section{Co-correspondence: Seock-Ah Im, MD, PhD} Department of Internal Medicine, Seoul National University Hospital, Cancer Research Institute, Seoul National University College of Medicine, 101 Daehak-ro, Jongno-gu, Seoul 03080, Korea Tel: $82-2-2072-0850$

Fax: 82-2-762-9662

E-mail: moisa@snu.ac.kr

Received June 23, 2016

Accepted July 27, 2016

Published Online August 23, 2016

*Seung Hoon Beom and Jisu Oh contributed equally to this work.

\section{Purpose}

Letrozole showed efficacy and generally favorable toxicities, along with the convenience of oral administration in postmenopausal patients with hormone receptor (HR)-positive metastatic breast cancer (MBC). To the best of our knowledge, there have been no reports of the clinical outcomes in Korean patients, although letrozole is widely used in practice. Therefore, this study was conducted to affirm the efficacy and toxicities of letrozole in Korean patients.

\section{Materials and Methods}

This study retrospectively analyzed $84 \mathrm{HR}$-positive $\mathrm{MBC}$ patients who had been treated with letrozole from January 2001 to December 2012. Clinicopathological characteristics and treatment history were extracted from medical records. All patients received $2.5 \mathrm{mg}$ letrozole once a day until there were disease progressions or unacceptable toxicity. Progression-free survival (PFS) was the primary endpoint, and secondary endpoints were overall survival (OS), objective response rate (ORR), and toxicity.

\section{Results}

The median age of the subjects was 59.3 years. Letrozole treatment resulted in a median PFS of 16.8 months (95\% confidence interval [Cl], 9.8 to 23.8) and a median OS of 56.4 months (95\% Cl, 38.1 to 74.7$)$. The ORR was $36.9 \%$ for the 84 patients with measurable lesions. Multivariate analysis revealed symptomatic visceral disease (hazard ratio, 3.437; $95 \% \mathrm{Cl}, 1.576$ to $7.495 ; \mathrm{p}=0.002$ ) and a disease-free interval $\leq 2$ years (hazard ratio, 2.697; $95 \% \mathrm{Cl}, 1.262$ to $5.762 ; \mathrm{p}=0.010$ ) were independently associated with shorter PFS. However, sensitivity to adjuvant hormone treatment was not related to PFS. Letrozole was generally well tolerated.

\section{Conclusion}

Letrozole showed considerable efficacy and tolerability as a first-line treatment in postmenopausal patients with HR-positive MBC.

\section{Key words}

Letrozole, Hormone receptor-positive, Metastatic breast cancer, First-line treatment, Korea 


\section{Introduction}

Breast cancer is the second most common cancer worldwide, with more than one million new cancer cases annually [1]. Breast cancer is also a major cancer in Korea [2]. Metastatic breast cancer (MBC) accounts for $20 \%-30 \%$ of all breast cancer cases and remains incurable; therefore, systemic therapy plays an essential role in the treatment of MBC. Among systemic therapies, endocrine therapy (ET) is the mainstay of treatment for patients with hormone receptor (HR)-positive MBC. Because ET is as effective as chemotherapy but less toxic, it should be recommended first in patients with HRpositive $\mathrm{MBC}$ except in cases of rapidly progressive disease [3].

Aromatase inhibitors (AIs) are commonly used in practice in adjuvant and palliative settings. AIs inhibit the aromatase enzyme, resulting in interruption of estrogen synthesis and suppression of tumor growth [4-7]. Currently, there are three clinically available third-generation AIs; two reversible nonsteroidal AIs, letrozole and anastrozole; and one irreversible steroidal AI, exemestane. All three agents are at least as effective as tamoxifen in postmenopausal patients with HRpositive MBC [4-6]. A randomized phase III clinical trial to compare letrozole with tamoxifen as first-line treatment showed that letrozole was superior to tamoxifen in terms of objective response rate (ORR), time to progression, and overall survival (OS) [6]. However, the majority of trials for AIs were conducted in Western patients. For this reason, there has been no satisfactory clinical data describing letrozole, particularly in Korean patients. Therefore, we investigated the efficacy and toxicity of letrozole as a first-line treatment for postmenopausal patients with HR-positive MBC.

\section{Materials and Methods}

\section{Study population}

We searched all patients who received letrozole as a palliative treatment regardless of ordinal lines of therapy between January 2001 and December 2012 (Fig. 1). A total of 407 patients met these criteria. Among the 407 patients, 230 who received prior chemotherapy and 90 treated with a second or further lines of treatment were excluded from our analysis. Menopause was defined as follows: prior bilateral oophorectomy, age $>60$ years, age $<60$ years with amenorrhea for 12 or more months in the absence of chemotherapy, tamoxifen, toremifene, ovarian suppression, or follicle-stimulating hormone/estradiol in the postmenopausal range [7]. This protocol was reviewed and approved by the Institutional Review Board of Seoul National University Hospital (SNUH) (IRB No. 1411-038-624). The recommendations of the Declaration of Helsinki were also observed.

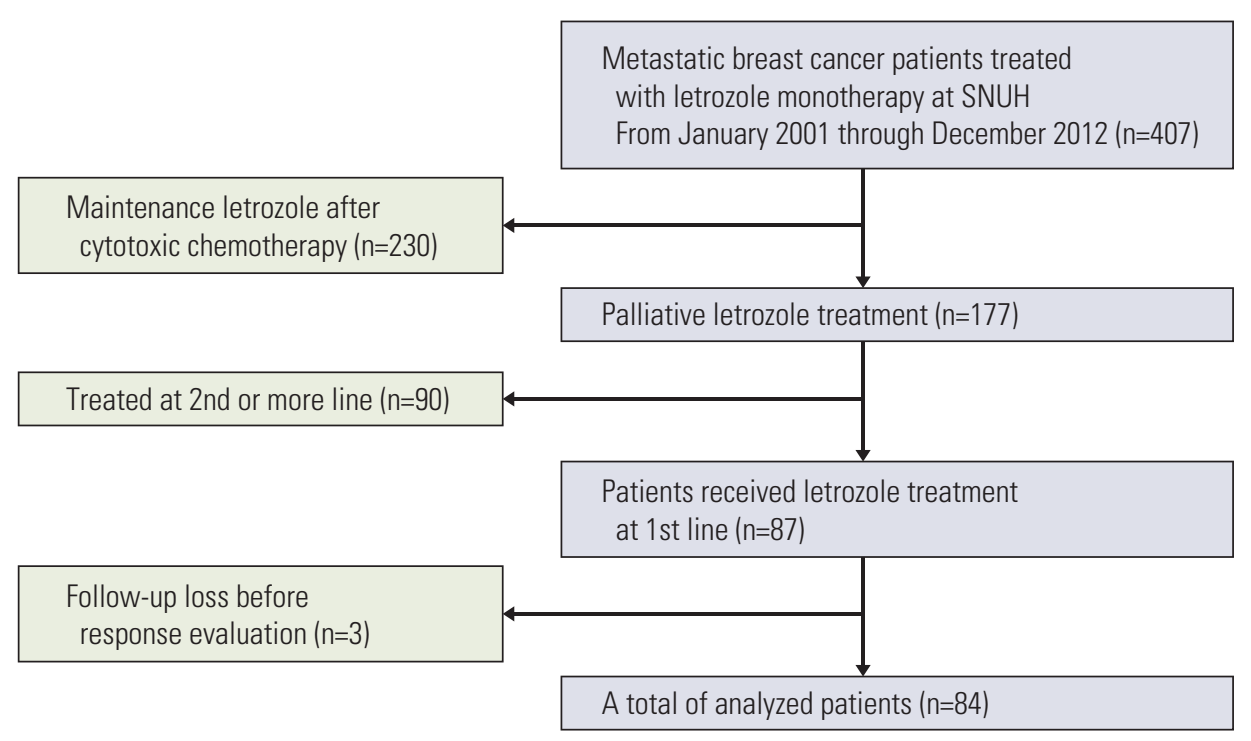

Fig. 1. CONSORT diagram of patients included in analysis. SNUH, Seoul National University Hospital. 


\section{Data collection}

We reviewed the medical records of all patients for the following characteristics: age, disease status, HR status, human epidermal growth factor receptor 2 (HER-2) status, Ki-67 status, adjuvant treatments, date of recurrence, cancer antigen 15-3 level, number of metastatic organs, and dominant metastatic site. estrogen receptor (ER) or progesterone receptor (PR) positivity was defined as staining for ER or PR $\geq 1 \%$ of tumor cells by immunohistochemistry (IHC). HER-2 positivity was defined as an IHC of $3+$ or $2+$ and HER-2 fluorescence in situ hybridization-positive. The high level of $\mathrm{Ki}-67$ was defined as an IHC of Ki- $67 \geq 14 \%$ of tumor cells [8]. The treatment response was evaluated according to the Response Evaluation Criteria in Solid Tumors ver. 1.1. The grading of toxicity was recorded according to the National Cancer Institute Common Toxicity Criteria for Adverse Events (NCI-CTCAE) ver. 4.0. ET-sensitive was defined as a relapse after $\geq 1$ year of completion of adjuvant ET. Diseasefree interval (DFI) was calculated from the day of curative resection to the date of tumor recurrence. Progression-free survival (PFS) was measured from the first day of letrozole treatment until tumor progressions or death of any cause. OS was calculated from the first day of letrozole treatment to patient death or the last date of follow-up. ORR was defined as the proportion of patients with either a complete response or a partial response. The clinical benefit rate (CBR) was defined as the proportion of patients achieving the best overall response of complete response, partial response, or stable disease lasting for at least 6 months.

\section{Treatment and follow-up}

All patients received $2.5 \mathrm{mg}$ letrozole once a day until disease progression or withdrawal due to toxicity or patient's decision. Tumor response was evaluated using the appropriate imaging modalities at least every 2 months in the first 6 months and every 3 months thereafter, or whenever there was clinical evidence of disease progression.

\section{Statistical analysis}

Categorical variables were compared with the Pearson's chi-square test or Fisher exact test, as appropriate. PFS and OS were calculated using the Kaplan-Meier method. The logrank test was used to compare the probability of survival between subgroups. Multivariate analysis was performed using the Cox proportional hazards model, and hazard ratios were calculated using a 95\% confidence interval. Two-sided $\mathrm{p}$-values of $<0.05$ were considered significant. All analyses were conducted using the PASW ver. 18.0 software package (SPSS Inc., Chicago, IL).

\section{Results}

\section{Clinicopathological characteristics}

A total of 84 patients with measurable disease were included in our study. Baseline characteristics of the entire study population are summarized in Table 1 . The mean age at diagnosis of the metastatic or recurrent disease was $59.3 \pm 10.5$ years (median, 59.3 years; range, 36.4 to 85.7 years). Overall, 54 patients $(64.3 \%)$ had both ER- and PR-positive tumor, while $27(32.1 \%)$ and three $(3.6 \%)$ had ER-positive / PR-negative tumor and ER-negative/PR-positive tumor, respectively. Seven patients $(8.3 \%)$ had HER2-positive breast cancer. Among 46 patients in whom Ki-67 could be determined, $10(11.9 \%)$ had a high level of Ki-67. Moreover, 34 patients $(40.5 \%)$ had bone-dominant metastasis and 21 patients $(25.0 \%)$ had lymph node or soft tissue metastasis. Among 48 patients who received adjuvant tamoxifen, $14(29.2 \%)$ had ET-sensitive tumors.

\section{Prior treatment}

A total of 74 patients (88.1\%) underwent curative surgery. Adjuvant ET data were insufficient for 26 patients; therefore, only $48(64.9 \%)$ received tamoxifen as an adjuvant ET. Moreover, only three patients received anastrozole following tamoxifen as sequential treatment, while $58(78.4 \%)$ received adjuvant chemotherapy. Additionally, 60 patients $(81.1 \%)$ had a DFI $>2$ years, and 14 patients $(29.2 \%)$ were ET-sensitive in the adjuvant ET group. The median DFI in ET-sensitive patients was 8.95 years (range, 6.25 to 18.3 years), while the median PFS and median OS were longer in the ET responsive group than the non-responsive group; however, these differences were not statistically significant (median PFS, 12.3 vs. 34.1 months; $\mathrm{p}=0.266$; median OS, 52.6 vs. 74.0 months; $\mathrm{p}=0.262$; log-rank test).

\section{The efficacy and survival analysis of letrozole}

The median follow-up was 71 months, and the median duration of treatment was 17.1 months. The most common reasons for discontinuing letrozole were disease progression $(97.6 \%)$, followed by drug toxicity (arthralgia grade 3, 2.4\%). The ORR and CBR were $36.9 \%$ and $82.1 \%$, respectively (Table 2). Median PFS and OS were 16.8 months (95\% confidence interval [CI], 9.8 to 23.8 ) and 56.4 months (95\% CI, 38.1 to 74.7 ), respectively (Fig. 2). Shorter PFS and OS were seen in patients with a DFI $\leq 2$ years or initial metastasis or symptomatic visceral disease (Fig. 3). 
Table 1. Clinicopathologic characteristics of patients

\begin{tabular}{|c|c|}
\hline Characteristic & No. of patients $(\%)$ \\
\hline Total & 84 \\
\hline Age, mean (range, yr) & $59.3(36.4-85.7)$ \\
\hline$<55$ & $29(34.5)$ \\
\hline$\geq 55$ & $55(65.5)$ \\
\hline \multicolumn{2}{|l|}{ Disease status } \\
\hline Relapsed disease & $74(88.1)$ \\
\hline Initially metastatic disease & $10(11.9)$ \\
\hline \multicolumn{2}{|l|}{ Hormonal receptor status ${ }^{\text {a) }}$} \\
\hline $\mathrm{ER}+, \mathrm{PR}+$ & $54(64.3)$ \\
\hline $\mathrm{ER}+, \mathrm{PR}-$ & $27(32.1)$ \\
\hline ER-, PR+ & $3(3.6)$ \\
\hline \multicolumn{2}{|l|}{ HER-2 status ${ }^{\text {b) }}$} \\
\hline Negative & $51(60.7)$ \\
\hline Positive & $7(8.3)$ \\
\hline Undetermined & $26(31.0)$ \\
\hline \multicolumn{2}{|l|}{ Ki-67 status ${ }^{c)}$} \\
\hline Low & $36(42.9)$ \\
\hline High & $10(11.9)$ \\
\hline Undetermined & $38(45.2)$ \\
\hline \multicolumn{2}{|c|}{ Prior treatment in relapsed cases $(n=74)$} \\
\hline \multicolumn{2}{|c|}{ Surgery $(\mathrm{n}=74)$} \\
\hline No & 0 \\
\hline Yes & $74(100)$ \\
\hline \multicolumn{2}{|l|}{ Adjuvant chemotherapy $(\mathrm{n}=74)$} \\
\hline No & $16(21.6)$ \\
\hline Yes & $58(78.4)$ \\
\hline Anthracycline based & $27(36.5)$ \\
\hline Anthracycline+Taxane & $9(12.2)$ \\
\hline CMF & $31(41.9)$ \\
\hline \multicolumn{2}{|l|}{ Adjuvant radiotherapy $(\mathrm{n}=74)$} \\
\hline No & $50(67.6)$ \\
\hline Yes & $24(32.4)$ \\
\hline \multicolumn{2}{|c|}{ Adjuvant hormone treatment $(\mathrm{n}=74)$} \\
\hline Unknown & $26(35.1)$ \\
\hline Yes & $48(64.9)$ \\
\hline Tamoxifen alone & 45 \\
\hline Tamoxifen $\rightarrow$ Anastrozole & 3 \\
\hline \multicolumn{2}{|l|}{ ET-responsiveness $(\mathrm{n}=48)$} \\
\hline No & $34(70.8)$ \\
\hline Sensitive & $14(29.2)$ \\
\hline \multicolumn{2}{|l|}{ Disease-free interval $(\mathrm{yr})(\mathrm{n}=74)$} \\
\hline$\leq 2$ & $14(18.9)$ \\
\hline$>2$ & $60(81.1)$ \\
\hline \multicolumn{2}{|l|}{ CA 15-3 level (U/mL) (n=84) } \\
\hline$\leq 30$ & $54(64.3)$ \\
\hline$>30$ & $19(22.6)$ \\
\hline Unknown & $11(13.1)$ \\
\hline \multicolumn{2}{|l|}{ Measurable disease $(n=84)$} \\
\hline No & $29(34.5)$ \\
\hline Yes & $55(65.5)$ \\
\hline
\end{tabular}

Table 1. Continued

\begin{tabular}{lc} 
Characteristic & No. of patients (\%) \\
$\begin{array}{ll}\text { No. of metastatic organs }(\mathbf{n}=\mathbf{8 4}) \\
1\end{array}$ & $13(15.5)$ \\
$\quad \geq 2$ & $71(84.5)$ \\
Dominant metastatic site $(\mathbf{n}=\mathbf{8 4})$ & \\
$\quad$ Bone & $34(40.5)$ \\
Lymph node or soft tissue & $21(25.0)$ \\
Asymptomatic visceral metastasis & $13(15.5)$ \\
Symptomatic visceral metastasis & $16(19.0)$ \\
\hline
\end{tabular}

ER, estrogen receptor; PR, progesterone receptor; HER2, human epidermal growth factor receptor 2; CMF, cyclophosphamide+methotrexate +5 -fluorouracil; ET, endocrine treatment; CA 15-3, cancer antigen 15-3; IHC, immunohistochemistry. ${ }^{a} \geq 1 \%$ cells were positive for hormone receptor as assessed by IHC staining, b)IHC score 3+ or unequivocal amplification as assessed by fluorescence in situ hybridization were positive for HER-2 status, ${ }^{c} \geq 14 \%$ cells were high for Ki-67 as assessed by IHC.

Table 2. The best treatment responses to first-line letrozole

\begin{tabular}{lc} 
Best treatment response & No. of patients (\%) \\
CR+PR & $31(36.9)$ \\
SD & $47(56.0)$ \\
PD & $6(7.1)$ \\
Objective response rate $^{\mathrm{a})}$ & $31 / 84(36.9)$ \\
Clinical benefit rate $^{\mathrm{b})}$ & $69 / 84(82.1)$ \\
\hline
\end{tabular}

$\mathrm{CR}$, complete response; $\mathrm{PR}$, partial response; $\mathrm{SD}$, stable disease; $\mathrm{PD}$, progressive disease. ${ }^{\mathrm{a}}$ Defined as proportion of patients having the best overall response of either $\mathrm{CR}$ or $\mathrm{PR},{ }^{\mathrm{b}}$ Defined as the proportion of patients having the best overall response of CR, PR, or SD for at least 6 months.

\section{The univariate and multivariate analysis}

Subgroup analysis revealed that the ORR for patients with a DFI $>2$ years was significantly higher than that of patients with a DFI $\leq 2$ years ( $43.3 \%$ vs. $14.3 \%, p=0.044$ ) (Table 3 ). Univariate analysis revealed that short DFI ( $\leq 2$ years), initial metastasis and symptomatic visceral metastasis were significantly associated with short PFS (Table 4). However, ETresponsiveness did not affect PFS. Upon multivariate analysis, short DFI ( $\leq 2$ years), initial metastasis and symptomatic visceral metastasis also significantly influenced PFS (Table 4). 


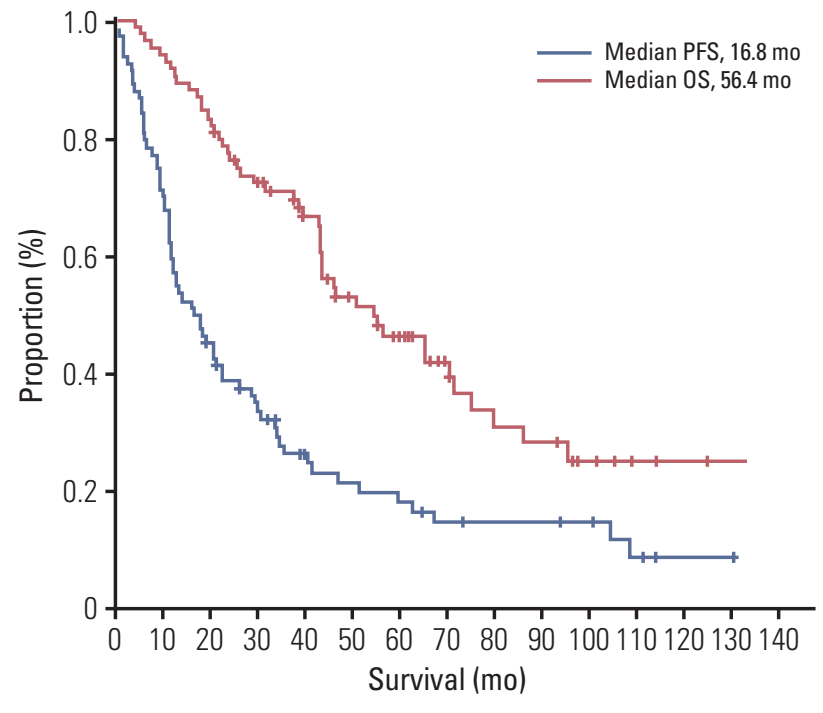

Fig. 2. Progression-free survival (PFS) and overall survival (OS) of first-line letrozole treatment.

\section{Toxicity}

The observed toxicity in our study was limited, with most adverse events being mild to moderate. Only two patients discontinued letrozole due to general weakness and arthralgia. Evaluation of bone health was available for 31 patients. Only one patient $(3.2 \%)$ had a left proximal humerus fracture related to osteoporosis, while two $(6.4 \%)$ had newly detected osteoporosis while using letrozole as defined by the NCICTCAE ver. 4.0.

\section{Discussion}

Upon meta-analysis [3], AIs showed similar efficacy and less toxicity than chemotherapy. The phase III trials $[5,6,9]$ demonstrated that anastrozole or letrozole was superior to tamoxifen as a first-line treatment in postmenopausal patients with MBC. Based on both meta-analysis and phase III trials, anastrozole or letrozole is the standard first-line therapy in postmenopausal patients with HR-positive MBC. However, most AI trials in $\mathrm{MBC}$ have been tested in Western patients, not Asian patients, and there have not been any data relevant to AIs generated in HR-positive MBC to date, particularly in Korean patients. Moreover, only $40 \%$ of Korean patients with breast cancer are postmenopausal [10], which seems to be lower than in Western countries. As a result, it is not easy to perform a large-scaled study for AIs, particularly in Korean postmenopausal patients. To the best of our knowledge, even though this is a retrospective analysis, our study has the largest scale of analysis for letrozole as a first-line treatment in Korean postmenopausal patients with HR-positive MBC.

In our study, PFS, OS, and ORR were 16.8 months, 56.4 months, and $36.9 \%$, respectively, which is more favorable than in other studies. Moreover, short DFI and symptomatic visceral metastasis were significantly related to poorer clinical outcomes (Table 4, Fig. 3). Unfortunately, we found no DFI data in phase III trials of and therefore could not compare them with our study directly. It is important to point out that even in the PO25 study [11], only the median DFI (5.9 years) was given. In our study, categorization of DFI was based on two years and the median DFI was 6.1 years (range, 0.1 to 37.4 years). Moreover, it is difficult to compare these values directly, because no previous studies divided patients into symptomatic and asymptomatic visceral metastasis. Rather, most studies conducted to date have used nonvisceral and visceral metastases to separate the dominant metastasis. Particularly, in visceral metastasis, only liver involvement was considered, not the symptoms. Therefore, our study is unique in that it confirms symptoms as an important factor.

A randomized phase III (PO25) trial to compare letrozole with tamoxifen in postmenopausal patients with $\mathrm{MBC}$ showed better clinical benefits in letrozole [6,11]. ORR appeared to be similar between our study and the PO25 study. However, PFS and OS in our study were better than in other trials, including the PO25 study. This result may have occurred because the proportion of patients with initial metastasis at diagnosis was much lower than in other phase III studies (Table 5), and most enrolled subjects were recurrent cases $(88.1 \%)$ in the present study. The disease burden of recurrent cases may have been smaller at the time of diagnosis since it was detected early through routine regular follow-up examination. The rate of dominant visceral metastasis was greater in the PO25 study (43\%) than in our study $(34.6 \%)$. Moreover, there were fewer patients with relatively adverse dominant metastatic sites such as liver involvement in this study (Table 5). In addition, one prior chemotherapy regimen for the treatment of metastatic disease was permitted in the PO25 trial, whereas our patients received letrozole treatment as their first-line therapy in the metastatic setting. It is also possible that the patients who were selected to be treated with first-line ET instead of chemotherapy had a tumor with a more indolent nature. Therefore, our results may show better survival than those of previous studies.

Even in the group with visceral metastasis, patients with no symptoms had a median PFS four times longer (40.6 months vs. 8.8 months) and a median OS three times longer 


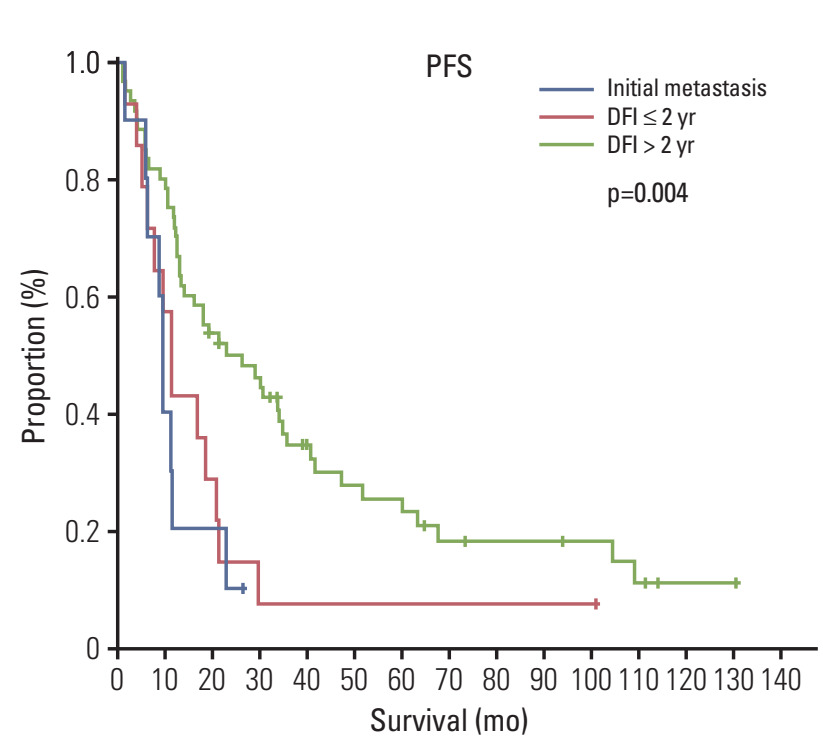

A
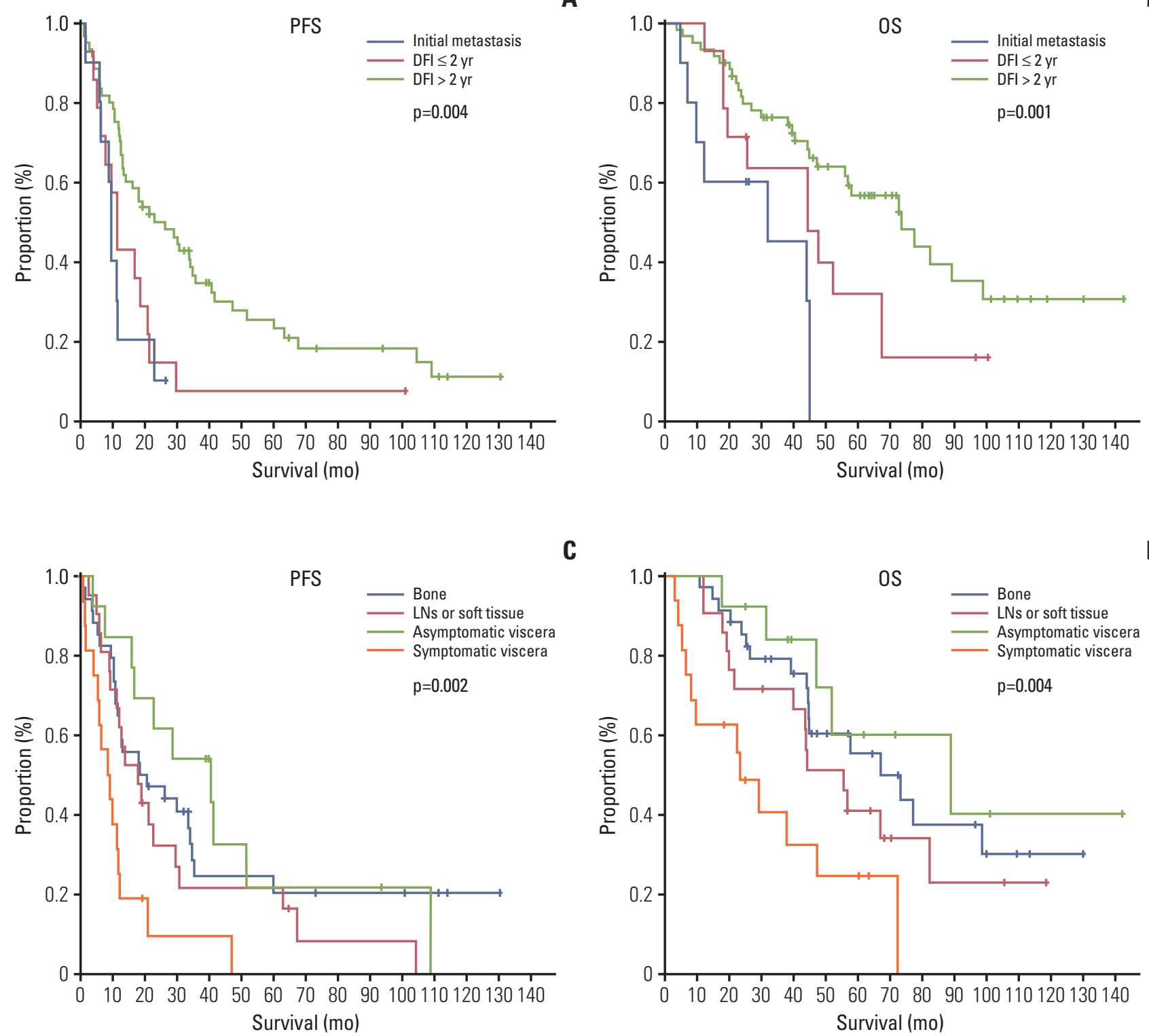

C

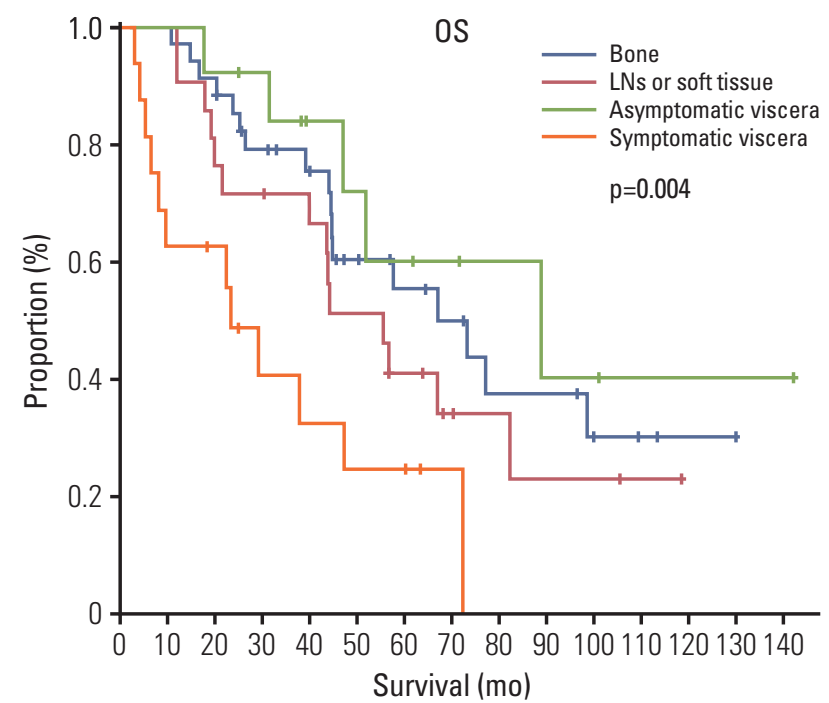

Fig. 3. Progression-free survival (PFS) (A) and overall survival (OS) (B) based on disease-free interval (DFI). Median PFS for initial metastasis, $\mathrm{DFI} \leq 2$ years and DFI $>2$ years: 9.3 months vs. 11.2 months vs. 22.8 months, $\mathrm{p}=0.004$, log-rank test; median OS: 32.4 months vs. 44.9 months vs. 74.0 months, $\mathrm{p}=0.001$, log-rank test. PFS (C) and OS (D) based on subgroups of dominant metastatic sites. Median PFS for bone, lymph nodes (LNs) or soft tissues, asymptomatic visceral metastasis, and symptomatic visceral metastasis: 18.5 months vs. 17.8 months vs. 40.6 vs. 8.8 months, $\mathrm{p}=0.002$, log-rank test; median OS: 67.8 months vs. 56.4 months vs. 89.5 vs. 24.2 months, $\mathrm{p}=0.004$, log-rank test.

(89.5 months vs. 24.2 months) than those with symptoms (Fig. 3). Moreover, patients with a DFI $\leq 2$ years or initial metastatic diseases also showed shorter survival than those without. Cytotoxic chemotherapy may be preferred for patients of a relatively young age, with short DFI, with initial metastasis or in need of rapid symptom control. Therefore, any of the third generation AIs may be used for front-line treatment of HR-positive MBC in postmenopausal patients without visceral crisis $[12,13]$. Treatment decisions are based on symptoms and disease severity (e.g., impending visceral crisis), DFI, patient age, performance status, sites of disease and comorbidities. Other important concerns include patient 
Table 3. Treatment responses in patient subgroups

\begin{tabular}{|c|c|c|c|c|}
\hline Prognostic factor & $\begin{array}{l}\text { Objective } \\
\text { response }\end{array}$ & p-value ${ }^{a}$ & $\begin{array}{l}\text { Clinical } \\
\text { benefit }\end{array}$ & p-value ${ }^{a)}$ \\
\hline \multicolumn{5}{|l|}{ Age $(y r)(n=84)$} \\
\hline$<55$ & $8 / 29(27.6)$ & 0.199 & $23 / 29(79.3)$ & 0.623 \\
\hline$\geq 55$ & $23 / 55(41.8)$ & & $46 / 55(83.6)$ & \\
\hline \multicolumn{5}{|l|}{ Hormone receptor status ${ }^{\mathrm{b})}(\mathrm{n}=84)$} \\
\hline Both receptors positive & $20 / 54(37.0)$ & 0.973 & $44 / 54(81.5)$ & 0.832 \\
\hline Only one receptor positive & $11 / 30(36.7)$ & & $25 / 30(83.3)$ & \\
\hline \multicolumn{5}{|l|}{ HER-2 status ${ }^{\mathrm{c}}(\mathrm{n}=84)$} \\
\hline Negative & $15 / 51(29.4)$ & 0.098 & $42 / 51(82.4)$ & 0.720 \\
\hline Positive & $2 / 7(28.6)$ & & $5 / 7(71.4)$ & \\
\hline Undetermined & $14 / 26(53.8)$ & & $22 / 26(84.6)$ & \\
\hline \multicolumn{5}{|l|}{ Ki-67 status ${ }^{\text {d) }}(\mathrm{n}=84)$} \\
\hline Low & $10 / 36(27.8)$ & 0.194 & $30 / 36(83.3)$ & 0.964 \\
\hline High & $3 / 10(30.0)$ & & $8 / 10(80.0)$ & \\
\hline Undetermined & $18 / 38(47.4)$ & & $31 / 38(81.6)$ & \\
\hline \multicolumn{5}{|l|}{ Disease status (n=74) } \\
\hline Disease-free interval $\leq 2 \mathrm{yr}$ & 2/14 (14.3) & 0.044 & $11 / 14(78.6)$ & 0.702 \\
\hline Disease-free interval > 2 yr & $26 / 60(43.3)$ & & $50 / 60(83.3)$ & \\
\hline \multicolumn{5}{|l|}{ No. of metastatic organs $(n=84)$} \\
\hline 1 & $3 / 13(23.1)$ & 0.355 & $11 / 13(84.6)$ & 1.000 \\
\hline$\geq 2$ & 28/71 (39.4) & & $58 / 71(81.7)$ & \\
\hline \multicolumn{5}{|l|}{ Dominant metastatic site $(\mathrm{n}=84)$} \\
\hline Bone & $9 / 34(26.5)$ & 0.217 & $29 / 34(85.3)$ & 0.136 \\
\hline Lymph node or soft tissue & $11 / 21(52.4)$ & & $18 / 21(85.7)$ & \\
\hline Asymptomatic visceral metastasis & $6 / 13(46.2)$ & & $12 / 13(92.3)$ & \\
\hline Symptomatic visceral metastasis & $5 / 16(31.3)$ & & $10 / 16(62.5)$ & \\
\hline \multicolumn{5}{|l|}{ ET-responsiveness $(n=48)$} \\
\hline No & $11 / 34(32.4)$ & 0.251 & $27 / 34(79.4)$ & 0.407 \\
\hline Sensitive & $7 / 14(50.0)$ & & $13 / 14(92.9)$ & \\
\hline
\end{tabular}

Values are presented as number (\%). HER-2, human epidermal growth factor receptor 2; ET, endocrine treatment; IHC, immunohistochemistry. ${ }^{\mathrm{a})} \mathrm{Chi}$-square test, ${ }^{\mathrm{b}} \geq 1 \%$ cells were positive for hormone receptors as assessed by IHC staining, ${ }^{\text {c) IHC }}$ score $3+$ or unequivocal amplification as assessed by fluorescence in situ hybridization were positive for HER-2 status, ${ }^{\text {d }} \geq 14 \%$ cells were high for Ki-67 as assessed by IHC.

preferences, maintaining or improving quality of life, and minimizing treatment toxicities. Even if patients had symptoms or metastatic diseases initially, an anti-hormone therapy would be useful when tumor tissues were revealed as strongly ER positive or it is difficult to proceed with chemotherapy because of old age. In our study, although patients had the above risk factors, they were treated with ET if they were elderly, had lower Eastern Cooperative Oncology Group performance scores, or did not want chemotherapy. To date, there has been no evidence of concurrent cytotoxic chemotherapy and cytostatic ET resulting in improved survival among advanced breast cancer patients. Therefore, we recommend ET and chemotherapy be performed sequentially to fit individual patients' situa- tions.

Endocrine resistance is a critical issue for patients with HRpositive MBC. Some tumors harbor intrinsic resistances to endocrine agents, and in the metastatic setting, all tumors ultimately acquire resistance to ET. In this study, there were no statistically significant differences in treatment response and survival between patients who had recurred after $\geq 1$ year of completion of adjuvant ET and those who had not. Patients with previous ET (tamoxifen) were included in the Phase III trials shown in Table 5, and third generation AIs drew favorable clinical outcomes. Moreover, the past tamoxifen treatment history did not affect the AI effect in any of the studies summarized in Table 5. There are different resistance mechanisms of tamoxifen and letrozole in genome-wide 
Table 4. Univariate and multivariate analyses of predictive factors for progression-free survival

\begin{tabular}{|c|c|c|c|c|}
\hline \multirow{2}{*}{ Prognostic factor } & \multicolumn{2}{|c|}{ Univariate } & \multicolumn{2}{|c|}{ Multivariate } \\
\hline & HR $(95 \%$ CI $)$ & p-value ${ }^{a)}$ & HR $(95 \%$ CI) & p-value ${ }^{a)}$ \\
\hline \multicolumn{5}{|l|}{ Age $(y r)(n=84)$} \\
\hline$<55$ & 1 & 0.782 & 1 & 0.793 \\
\hline$\geq 55$ & $1.073(0.652-1.765)$ & & $1.085(0.590-1.998)$ & \\
\hline \multicolumn{5}{|l|}{ Hormone receptor status $^{\mathrm{b})}(\mathrm{n}=84)$} \\
\hline Both receptors positive & 1 & 0.798 & 1 & 0.375 \\
\hline One receptor positive only & $1.067(0.649-1.753)$ & & $1.285(0.738-2.240)$ & \\
\hline \multicolumn{5}{|l|}{ HER-2 status ${ }^{c}(n=84)$} \\
\hline Negative & 1 & 0.291 & 1 & 0.642 \\
\hline Positive & $1.134(0.664-1.936)$ & 0.644 & $0.709(0.279-1.804)$ & 0.471 \\
\hline Undetermined & $1.977(0.829-4.716)$ & 0.124 & $0.790(0.437-1.426)$ & 0.434 \\
\hline \multicolumn{5}{|l|}{ Ki-67 status ${ }^{\text {d) }}(n=84)$} \\
\hline Low & 1 & 0.401 & 1 & 0.341 \\
\hline High & $1.474(0.709-3.065)$ & 0.299 & $1.964(0.735-5.247)$ & 0.178 \\
\hline Undetermined & $0.903(0.540-1.512)$ & 0.699 & $1.457(0.784-2.708)$ & 0.234 \\
\hline \multicolumn{5}{|l|}{ Disease status $(\mathrm{n}=84)$} \\
\hline Disease-free interval > 2 yr & 1 & 0.004 & 1 & 0.009 \\
\hline Disease-free interval $\leq 2 \mathrm{yr}$ & $2.051(1.095-3.840)$ & 0.025 & $2.697(1.262-5.762)$ & 0.010 \\
\hline Initially metastatic disease & $2.907(1.376-6.140)$ & 0.005 & $2.519(1.113-5.703)$ & 0.027 \\
\hline \multicolumn{5}{|l|}{ No. of metastatic organs $(n=84)$} \\
\hline 1 & 1 & 0.174 & 1 & 0.230 \\
\hline$\geq 2$ & $1.675(0.797-3.523)$ & & $1.635(0.733-3.646)$ & \\
\hline \multicolumn{5}{|l|}{ Dominant metastatic site $(n=84)$} \\
\hline Bone & 1 & 0.002 & 1 & 0.004 \\
\hline Lymph node or soft tissue & $1.380(0.756-2.519)$ & 0.294 & $1.122(0.552-2.282)$ & 0.750 \\
\hline Asymptomatic visceral metastasis & $0.813(0.389-1.696)$ & 0.581 & $0.721(0.331-1.572)$ & 0.411 \\
\hline Symptomatic visceral metastasis & $3.077(1.584-5.975)$ & 0.001 & $3.437(1.576-7.495)$ & 0.002 \\
\hline \multicolumn{5}{|l|}{ ET-responsiveness $(\mathrm{n}=48)$} \\
\hline No & 1 & 0.252 & 1 & 0.455 \\
\hline Sensitive & $0.680(0.351-1.317)$ & & $0.749(0.352-1.597)$ & \\
\hline
\end{tabular}

$\mathrm{HR}$, hazard ratio; CI, confidence interval; HER-2, human epidermal growth factor receptor 2; ET, endocrine treatment; IHC, immunohistochemistry. ${ }^{\text {a) }}$ Cox proportional hazard model, ${ }^{b} \geq 1 \%$ cells were positive for hormone receptor as assessed by IHC staining, ${ }^{\text {c) }} \mathrm{IHC}$ score $3+$ or unequivocal amplification as assessed by fluorescence in situ hybridization were positive for HER-2 status, ${ }^{\mathrm{d}} \geq 14 \%$ cells were high for Ki-67 as assessed by IHC.

analysis [14]; therefore, these findings suggest that there no cross-resistance between these mechanisms. However, the mechanisms underlying resistance to ET are complex [15]. Recent studies of PALOMA-1 [16], and Turner et al. [17] demonstrated that endocrine monotherapy had limited efficacy in patients with disease progression after previous exposure to ET, irrespective of clinically or molecularly defined endocrine sensitivity, suggesting a need for the routine use of more effective combination regimens. In our study, the clinical outcomes with no statistically significant difference according to ET-responsiveness might have occurred because of the relatively small sample sizes. Therefore, further studies and validation are warranted.
It should be noted that our study had the following limitations. First, the retrospective design made it difficult to compare functional status, symptoms, and toxicity profiles among patients. Second, the enrolled patients were selected from a single institution in Korea, and the relatively small sample size may limit the statistical power to derive significant outcomes and correct the differences in subgroup characteristics. Despite these limitations, our analysis investigated a homogeneous patient population with a large case series of postmenopausal women treated with the first line letrozole that were regularly evaluated during and after treatment. 
Table 5. Phase III trials using AIs as first-line treatment in postmenopausal patients with MBC

\begin{tabular}{|c|c|c|c|c|}
\hline & $\begin{array}{c}\text { Bonneterre } \\
\text { et al. [5] }\end{array}$ & $\begin{array}{l}\text { Nabholtz } \\
\text { et al. [9] }\end{array}$ & $\begin{array}{l}\text { Mouridsen } \\
\text { et al. }[6,18]\end{array}$ & Our study \\
\hline Design & Phase III & Phase III & Phase III & $\begin{array}{l}\text { Retrospective } \\
\text { analysis }\end{array}$ \\
\hline Population & $\begin{array}{l}\text { Europe, } \\
\text { Australia, } \\
\text { New Zealand, } \\
\text { South America, } \\
\text { South Africa }\end{array}$ & $\begin{array}{l}\text { USA, } \\
\text { Canada }\end{array}$ & $\begin{array}{l}\text { Europe, } \\
\text { North America, } \\
\text { South America, } \\
\text { South Africa, } \\
\text { India, Egypt, Israel }\end{array}$ & Korea \\
\hline Investigating agent & $\begin{array}{l}\text { Anastrozole } \\
(\mathrm{n}=340)\end{array}$ & $\begin{array}{l}\text { Anastrozole } \\
(\mathrm{n}=171)\end{array}$ & $\begin{array}{l}\text { Letrozole } \\
(n=453)\end{array}$ & $\begin{array}{l}\text { Letrozole } \\
(\mathrm{n}=84)\end{array}$ \\
\hline Age, mean (range, yr) & $67(34-91)$ & 68 & $65(31-96)$ & $59(36-86)$ \\
\hline \multicolumn{5}{|l|}{ Disease status at first diagnosis } \\
\hline Initial metastasis (\%) & 48 & 30 & 32 & 12 \\
\hline Relapse $(\%)$ & 52 & 69 & 68 & 88 \\
\hline Overall response rate $(\%)$ & 32.9 & 21 & 32 & 37 \\
\hline Median time to progression (mo) & 8.2 & 11.1 & 9.4 & 16.8 \\
\hline Nonvisceral metastasis, n (\%) & $237(69.7)$ & $88(51.5)$ & $258(57)$ & $55(65.5)$ \\
\hline Median TTP (mo) & - & - & 10.9 & 18.1 \\
\hline Viscera metastasis without liver involvement, $\mathrm{n}(\%)$ & $71(20.9)$ & $70(40.9)$ & $135(29.8)$ & $26(31)$ \\
\hline Median TTP (mo) & - & - & 11.9 & 16.8 \\
\hline Viscera metastasis with liver involvement, $\mathrm{n}(\%)$ & $32(9.4)$ & $13(7.6)$ & $60(13.2)$ & $3(3.6)$ \\
\hline Median TTP (mo) & - & - & 3.8 & 10.0 \\
\hline
\end{tabular}

$\mathrm{AI}$, aromatase inhibitor; $\mathrm{MBC}$, metastatic breast cancer.

\section{Conclusion}

Letrozole showed good efficacy and tolerability in Korean postmenopausal patients. However, the characteristics of Korean patients differ from those of Western patients in terms of age, menopausal status and disease status at first diagnosis. Therefore, a prospective clinical trial to reveal the efficacy and toxicity of AIs in Korean patients is warranted.

\section{Conflicts of Interest}

Conflict of interest relevant to this article was not reported.

\section{Acknowledgments}

This research was supported by the Basic Science Research Program through the National Research Foundation of Korea (NRF) funded by the Ministry of Science, ICT and future Planning (2015R1A2A2A01004655) and partly supported by grants from Seoul National University College of Medicine (0431-20140006). We also sincerely appreciate Mrs. MyungHwa Lee and Mr. Hyuk Jin Chung for their dedication to cancer research funding even though Mrs. Lee suffered from metastatic breast cancer. 


\section{References}

1. Ferlay J, Soerjomataram I, Dikshit R, Eser S, Mathers C, Rebelo $\mathrm{M}$, et al. Cancer incidence and mortality worldwide: sources, methods and major patterns in GLOBOCAN 2012. Int J Cancer. 2015;136:E359-86.

2. Jung KW, Won YJ, Kong HJ, Oh CM, Seo HG, Lee JS. Prediction of cancer incidence and mortality in Korea, 2013. Cancer Res Treat. 2013;45:15-21.

3. Wilcken N, Hornbuckle J, Ghersi D. Chemotherapy alone versus endocrine therapy alone for metastatic breast cancer. Cochrane Database Syst Rev. 2003;(2):CD002747.

4. Paridaens RJ, Dirix LY, Beex LV, Nooij M, Cameron DA, Cufer $\mathrm{T}$, et al. Phase III study comparing exemestane with tamoxifen as first-line hormonal treatment of metastatic breast cancer in postmenopausal women: the European Organisation for Research and Treatment of Cancer Breast Cancer Cooperative Group. J Clin Oncol. 2008;26:4883-90.

5. Bonneterre J, Thurlimann B, Robertson JF, Krzakowski M, Mauriac L, Koralewski P, et al. Anastrozole versus tamoxifen as first-line therapy for advanced breast cancer in 668 postmenopausal women: results of the Tamoxifen or Arimidex Randomized Group Efficacy and Tolerability study. J Clin Oncol. 2000;18:3748-57.

6. Mouridsen H, Gershanovich M, Sun Y, Perez-Carrion R, Boni C, Monnier A, et al. Phase III study of letrozole versus tamoxifen as first-line therapy of advanced breast cancer in postmenopausal women: analysis of survival and update of efficacy from the International Letrozole Breast Cancer Group. J Clin Oncol. 2003;21:2101-9.

7. Carlson RW, Allred DC, Anderson BO, Burstein HJ, Carter WB, Edge SB, et al. Breast cancer: clinical practice guidelines in oncology. J Natl Compr Canc Netw. 2009;7:122-92.

8. Cheang MC, Chia SK, Voduc D, Gao D, Leung S, Snider J, et al. Ki67 index, HER2 status, and prognosis of patients with luminal B breast cancer. J Natl Cancer Inst. 2009;101:736-50.

9. Nabholtz JM, Buzdar A, Pollak M, Harwin W, Burton G, Mangalik A, et al. Anastrozole is superior to tamoxifen as first-line therapy for advanced breast cancer in postmenopausal women: results of a North American multicenter randomized trial. Arimidex Study Group. J Clin Oncol. 2000;18:3758-67.

10. Kim Z, Min SY, Yoon CS, Jung KW, Ko BS, Kang E, et al. The basic facts of Korean breast cancer in 2012: results from a nationwide survey and breast cancer registry database. J Breast Cancer. 2015;18:103-11.

11. Mouridsen H, Gershanovich M, Sun Y, Perez-Carrion R, Boni C, Monnier A, et al. Superior efficacy of letrozole versus tamoxifen as first-line therapy for postmenopausal women with advanced breast cancer: results of a phase III study of the International Letrozole Breast Cancer Group. J Clin Oncol. 2001;19:2596-606.

12. Gibson L, Lawrence D, Dawson C, Bliss J. Aromatase inhibitors for treatment of advanced breast cancer in postmenopausal women. Cochrane Database Syst Rev. 2009;(4):CD003370.

13. Kataja V, Castiglione M; ESMO Guidelines Working Group. Locally recurrent or metastatic breast cancer: ESMO clinical recommendations for diagnosis, treatment and follow-up. Ann Oncol. 2008;19 Suppl 2:ii11-3.

14. Masri S, Phung S, Wang X, Wu X, Yuan YC, Wagman L, et al. Genome-wide analysis of aromatase inhibitor-resistant, tamoxifen-resistant, and long-term estrogen-deprived cells reveals a role for estrogen receptor. Cancer Res. 2008;68: 4910-8.

15. Murphy CG, Dickler MN. Endocrine resistance in hormoneresponsive breast cancer: mechanisms and therapeutic strategies. Endocr Relat Cancer. 2016;23:R337-52.

16. Finn RS, Crown JP, Lang I, Boer K, Bondarenko IM, Kulyk SO, et al. The cyclin-dependent kinase $4 / 6$ inhibitor palbociclib in combination with letrozole versus letrozole alone as first-line treatment of oestrogen receptor-positive, HER2-negative, advanced breast cancer (PALOMA-1/TRIO-18): a randomised phase 2 study. Lancet Oncol. 2015;16:25-35.

17. Turner NC, Ro J, Andre F, Loi S, Verma S, Iwata H, et al. Palbociclib in hormone-receptor-positive advanced breast cancer. N Engl J Med. 2015;373:209-19.

18. Mouridsen HT. Letrozole in advanced breast cancer: the PO25 trial. Breast Cancer Res Treat. 2007;105 Suppl 1:19-29. 